REVIEW

\title{
Epidemiology of gastric cancer in Japan
}

\author{
$M$ Inove, $S$ Tsugane
}

Postgrad Med J 2005;81:419-424. doi: 10.1136/pgmj.2004.029330

Despite its decreasing trend in Japan, gastric cancer remains an important public health problem. Although the age standardised rates of gastric cancer have been declining for decades, the absolute numbers are increasing because of the rapid aging of the population. A large proportion of Japanese gastric cancers are detected at an early stage, with a better overall survival rate. As with Western developed countries, a change in the social environment such as reduced salt use and increased fresh vegetable and fruit intake as well as improvement of food storage may play an important part in the decline. Differences in Helicobacter pylori infection rates between generations presumably have contributed to the generation related variation in the declining trends. It is expected that most gastric cancers in Japan may be preventable by lifestyle modification such as salt reduction and increased fruit and vegetable intake, together with avoidance of smoking and countermeasures against $H$ pylori infection so that the level now evident in Western developed countries can be reached.

\begin{abstract}
See end of article for authors' affiliations

Correspondence to: Dr M Inove, Epidemiology and Prevention Division, Research Centre for Cancer Prevention and Screening, National Cancer Centre, 5-1-1 Tsukiji, Chuo-ku, Tokyo 104-0045, Japan; mnminove@gan2.res.ncc. go.jp
\end{abstract}

Submitted 2 October 2004 Accepted

19 November 2004
D espite its decreasing trend over many decades, gastric cancer remains a major public health problem in the world. In this review, recent epidemiological findings on Japanese gastric cancer are discussed to provide an up to date perspective.

\section{DESCRIPTIVE FEATURES \\ World trend}

According to the world estimate of cancer incidence in the year 2002 by the International Agency for Research on Cancer, ${ }^{1}$ gastric cancer is still one of the most common cancers in the world, the fourth most commonly occurring cancer ( $9 \%$ of all cancers) after cancer of the lung, breast, and colorectum, and the second most common cancer related cause of death (10\% of all cancer deaths) after lung cancer. In 2002, the incidence of gastric cancer was estimated at 934000 cases, 56\% of the new cases being derived from Eastern Asia, 41\% from China, and $11 \%$ from Japan. On the whole, $65 \%-70 \%$ of incident cases and deaths from gastric cancer are occurring in less developed countries.

The number of cases and the cancer related death rate tend to be influenced by population size and age distribution, especially the proportion of the elderly population. By applying age standardised rates that included adjustment for such artefacts, Japanese gastric cancer rate ranks the highest along with that in Korea (fig 1). The highest incidence rate is observed in Eastern Asia, Eastern Europe, and South America, and the lowest rates are in North America, Oceania, Northern Europe, South east Asia, and South Asia. It is known that gastric cancer as a whole is more common in men, the male to female ratio of the incidence ranging from 1.5 to 3, although this varies with the age group, values of greater than 1 only in middle aged and elderly groups. ${ }^{1}$ In addition, the proportion of the undifferentiated type, in other words, the diffuse type, of gastric cancer is higher among female or young patients than among men or elderly people.

In most countries, gastric cancer shows a constant declining trend..$^{2-10}$ Even where gastric cancer occurs infrequently nowadays such as in the USA and Northern Europe, it was recognised in the past as one of the major cancers, and a dramatic reduction in the incidence of gastric cancer has occurred.

\section{Time trend in Japan}

In Japan, gastric cancer was ranked as the most common cancer in the past, but this aspect has gradually been changing in recent years. Japanese gastric cancer has been overtaken by lung cancers as the leading cause of cancer related death since 1999, then accounting for $16 \%$ (49 500 deaths) of all deaths from cancer that occurred in 2003. ${ }^{11}$ By sex, death from gastric cancer was overtaken by lung cancer in men and by colorectal cancer in women. The incidence, however, continues to be the highest among all cancers. The latest estimate shows a total of 104000 cases of gastric cancer occurred in 1999 (20\% of all cancers) followed by lung cancer with 63300 patients who developed lung cancer. ${ }^{12}$ By sex, the incidence of gastric cancer continues to be the highest among men, while in women, it was overtaken by breast cancer. Although age standardised incidence and death rates have been declining for decades, the absolute number of cases of gastric cancer shows an increasing trend (fig 2). The inverse trend between the absolute numbers and age standardised rates is considered to be attributable to the rapid aging of the population. The trend towards a decline is more prominent in younger than in older age groups, and there is an increasing trend only among those aged 85 and over. The average age at death from gastric cancer has also shown an increase from 61 in 1950 to 73 in $2000 .^{2}$ Improvement of diagnosis for elderly people and the increased age at diagnosis may play a part.

Studies on Japanese migrants show that the incidence in the offspring of Japanese migrants tends to approach that in their host countries, 


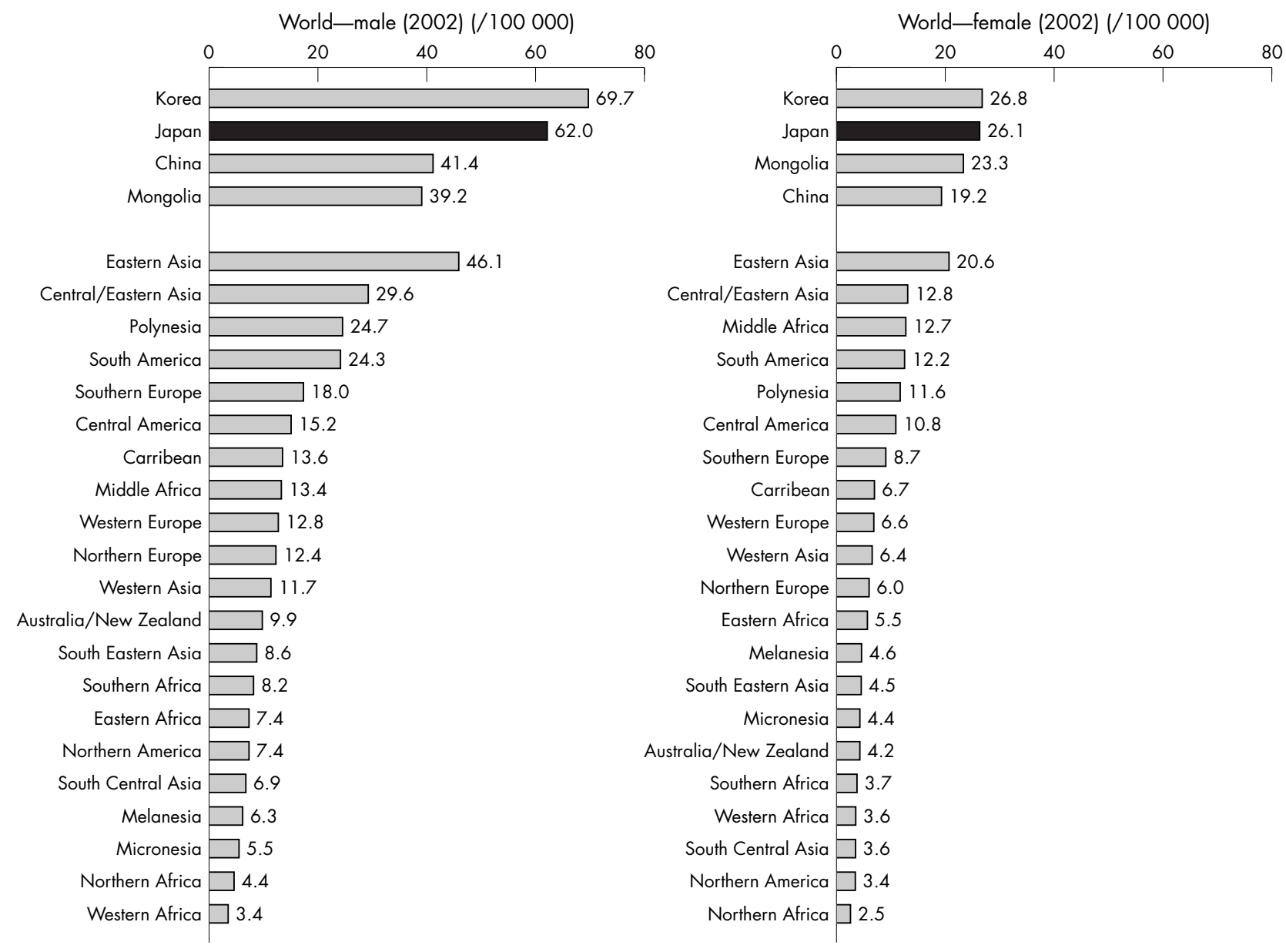

Figure 1 Age standardised incidence rate of gastric cancer in the world (2002). Source: Ferlay et al.'

with the degree of reduction dependent on the degree of Westernisation and the actual incidence rate in the respective host countries. In a comparison between Japanese migrants to the USA and Brazil, two major target countries for Japanese migration, Japanese migrants to the USA show a significantly lower incidence rate than Japanese living in Japan, while Japanese migrants to Brazil show a similar rate to the latter group. ${ }^{13}$ This suggests that the traditional Japanese dietary practice, retained among Japanese migrants to Brazil than those to the USA, contributes as a risk factor for this cancer.

\section{CLINICOEPIDEMIOLOGICAL FEATURES}

Japanese gastric cancers as a group show characteristic features. Firstly, the distal stomach is more frequent as the site of occurrence than the proximal portion. With clinicopathological finding of surgical cases, around $80 \%$ of cases are located in the middle or lower thirds of the stomach. ${ }^{14}{ }^{15}$ The proportion of the distal cancers increases when restricted to early gastric cancers detected at an early stage ${ }^{16}$ and to cases in the elderly population. ${ }^{17}$ Similar features are also corroborated by population based data, although such data are limited by a high proportion of cancers with an unknown location. $^{3}$ About $15 \%$ of cancers seen in the Japanese registries are located in the upper portion of the stomach (fig 3).

Secondly, although the prognosis for gastric cancer is generally poor, better survival rates are seen in Japanese patients. An international comparison, based on population based cancer registries in developing countries and Western developed countries, shows a five year relative survival rate of about $20 \%,{ }^{18-20}$ while it is $40 \%-60 \%$ in Japan (fig 4 ). ${ }^{21}{ }^{22}$ The comparatively good overall survival in Japan is considered to be attributable to the large proportion of gastric cancer diagnosed at an early stage in Japanese patients. In 1995$2000,53 \%$ of Japanese gastric cancers were localised when diagnosed ${ }^{23}$ which is comparatively high as compared with the $27 \%$ reported by the US SEER programme (fig 5). ${ }^{18} \mathrm{~A}$ similar low rate of localisation is speculated to exist in other Western countries. In addition, a report from a population based registry has indicated that the overall five year survival rates for gastric cancer improved from $28 \%$ for cases diagnosed in 1975-77 to $50 \%$ for those in 1990-92. On the basis of the clinical extent, the survival rate for localised cases improved from $65 \%$ for those diagnosed in 1975-77 to $86 \%$ for those after 1981-83, while the respective figures for nonlocalised cases were $23 \%$ to $32 \%$. No improvement was seen for cases with distant metastases. ${ }^{24}$ Thus, the increase in the proportion of cases detected at an early stage may have made a strong contribution to the improvement in overall survival. It has also been found that the survival rate increases in tandem with the increase in the proportion of gastroscopic examinees, but not with the increase in cases detected by screening. ${ }^{24}$ A recent report pointed out that in Japan, the group of localised cancer included intramucosal tumours, while such cases would not be included as gastric cancers in Western countries. This bias may influence the proportion of localised cancer and with survival. ${ }^{25}$ However, a Japanese follow up study of early gastric cancer including intramucosal cases has reported the progression of these cancers to an 

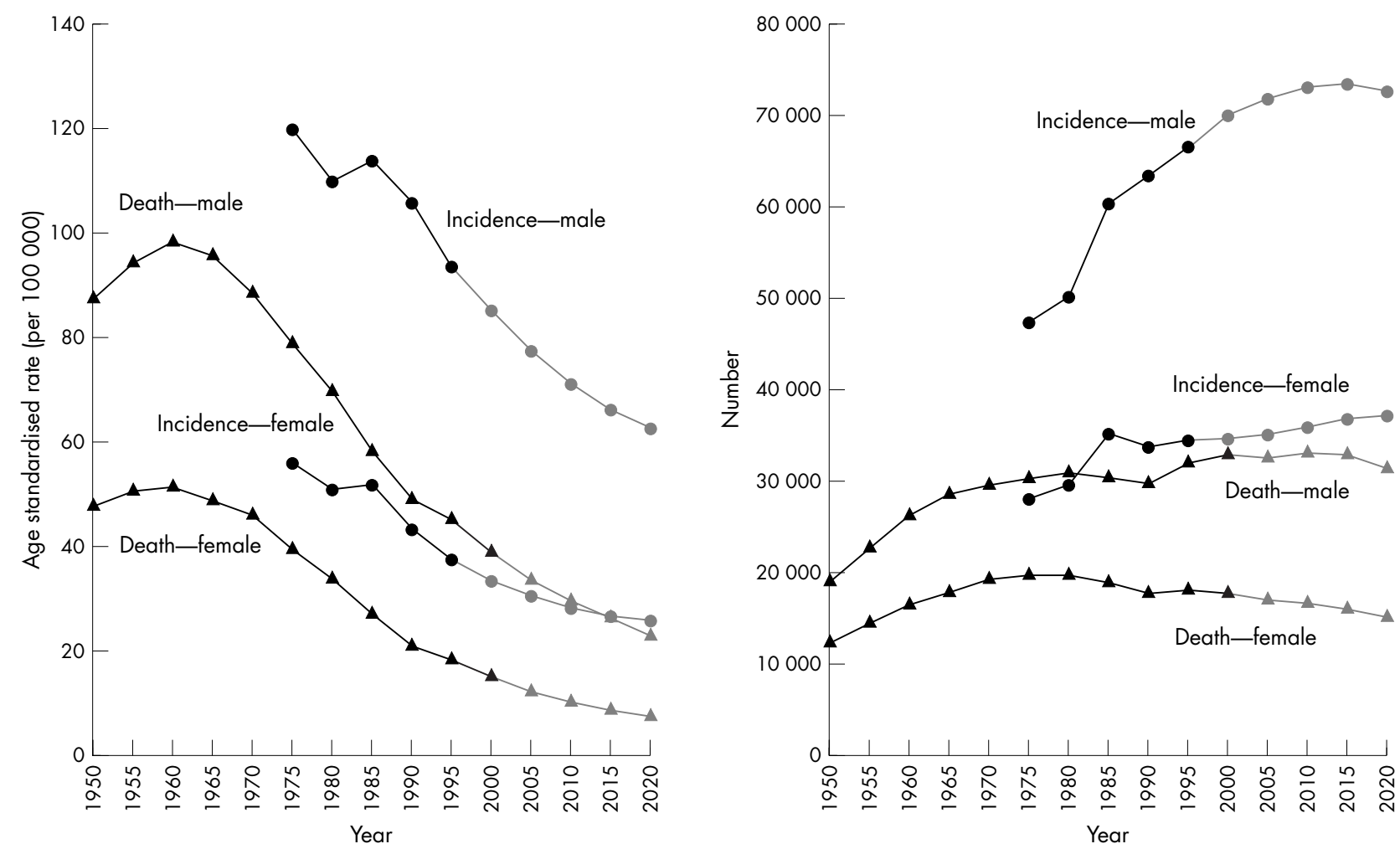

Figure 2 Trend in the incidence of and death from gastric cancer in the Japanese population (rate adjusted by Japanese model population in 1985) Source: Tajima et $a^{2}$ and Oshima et al..$^{22}$

advanced stage with time and that they led to death if left untreated. ${ }^{26}$

\section{RISK FACTORS AND PREVENTION}

A dramatic reduction in gastric cancer has occurred in Western developed countries over the past century. In these countries, no active primary and secondary prevention measures were introduced, instead, changes in the social environment, such as reduced salt use and increased fruit and fresh vegetable consumption associated with improved food storage with freezers and refrigerators are generally considered to have had important parts in the reduction of gastric cancer cases. These factors may also be applicable in Japan. ${ }^{27}$ According to the report of a joint WHO/FAO Expert Consultation in 2003, although insufficient evidence existed to grade dietary factors as either a "convincing" risk or protective factors, a high intake of salt preserved foods and salt and reduced fruit and vegetable intake were evaluated as a "probable" risk factor of gastric cancer. ${ }^{28}$ The association between smoking and gastric cancer is well established, and an evaluation from the International Agency for Research on Cancer concludes that smoking is one of the convincing risk factors for gastric cancer. ${ }^{29}$ Positive association with chronic atrophic gastritis, drinking habits, barbecued or grilled cooking and an inverse association with green tea are considered also to be possible modifying factors. ${ }^{30}$

In addition, Helicobacter pylori infection is considered as an important risk factor of gastric cancer. In Japanese asymptomatic populations, the prevalence of $H$ pylori varies with age; with infection seen in less than $50 \%$ of subjects under the age of 30 as compared with an infection rate of as high as $70 \%-$ $80 \%$ in those aged 50 and over. ${ }^{31-34}$ It has also been found that the $H$ pylori positive rate increased at $1 \%$ per year for those born after 1950 but was high and comparatively constant for people with birth dates before $1950 .{ }^{31}$ The infection status in adults is considered to be influenced by the socioeconomic status in childhood. Given the massive improvement in hygiene and the economic environment in Japan in the postwar decades, differences in the infection rates between generations presumably have contributed to the variation in the declining trends in incidence and death rates of gastric cancer among Japanese when the cases are grouped according to their year of birth. On the other hand, considering the high prevalence even in the low gastric cancer rate areas of south east $\mathrm{Asia},^{35}$ and that a small proportion of subjects with $H$ pylori infection develop gastric cancer during their lifetime, to contribute to the risk of gastric cancer, infection with $H$ pylori presumably must interact with other factors, including dietary habits, host factors, and virulence of the $H$ pylori infection.

A mass screening programme with photofluorography for gastric cancer has been conducted in Japan since 1960. Over six million Japanese attend the screening annually, the participation rate being $10 \%-20 \%$ of the target population. Previous reports showed an acceptable accuracy of early detection with the screening programme and better prognosis for screen detected cancer cases. ${ }^{36}$ On the other hand, descriptive data show that the age standardised death rates declined almost in parallel with the incidence rate in the 1960s, while the gap between them became wider after the 1970s. As the rate of both incidence and death have been declining, it seems that the reduction in the rates is attributable mainly to changes in these environmental factors and the discrepancy between the incidence and death rates can be explained in part by efforts made to achieve early detection. ${ }^{37}$

\section{FUTURE PROJECTION AND PERSPECTIVE}

According to future projections, both age standardised incidence and death rates will consistently decrease, with a 


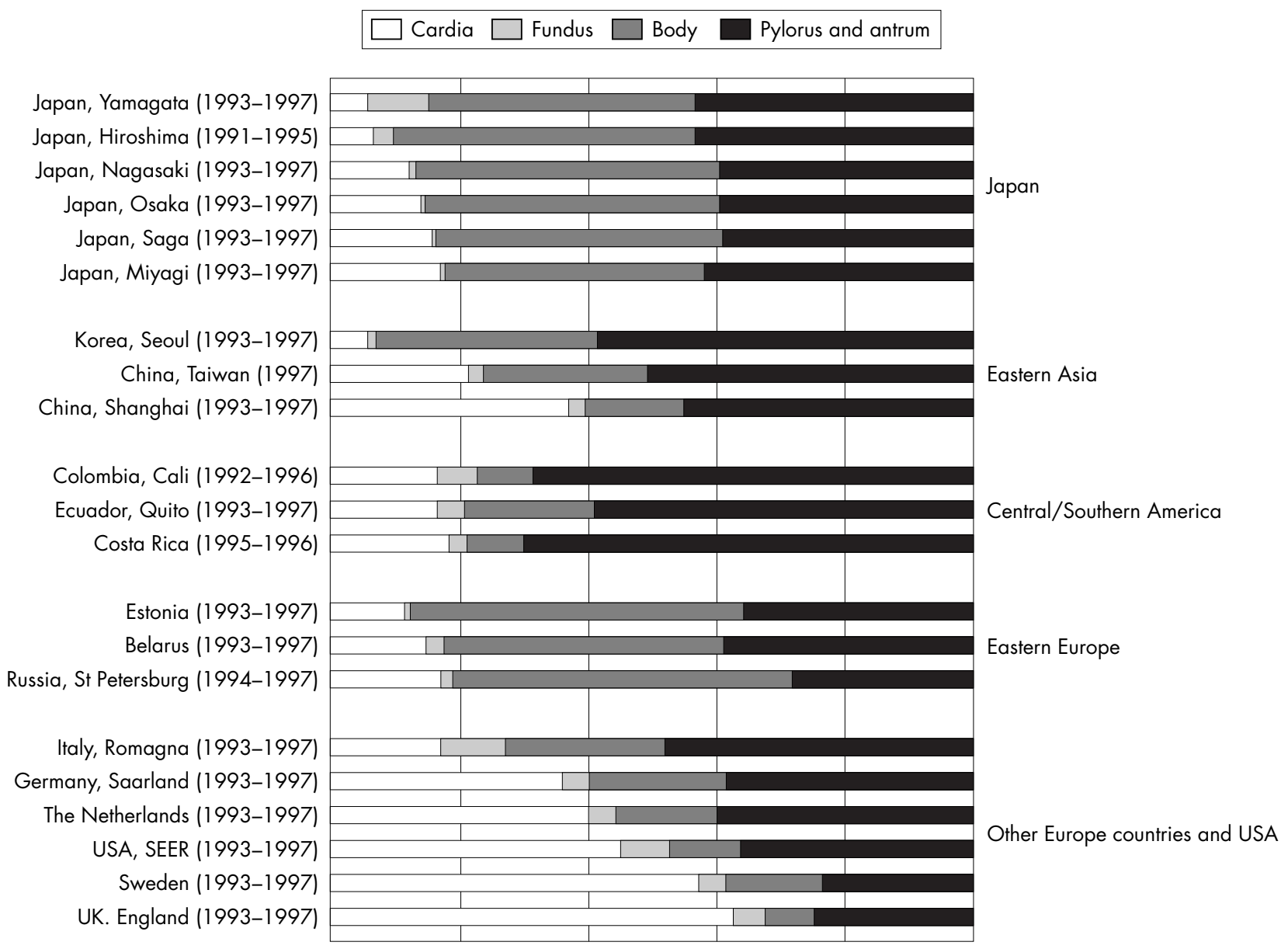

Figure 3 International comparison of subsite distribution of gastric cancer (both sexes). Source Parkin et al. ${ }^{3}$

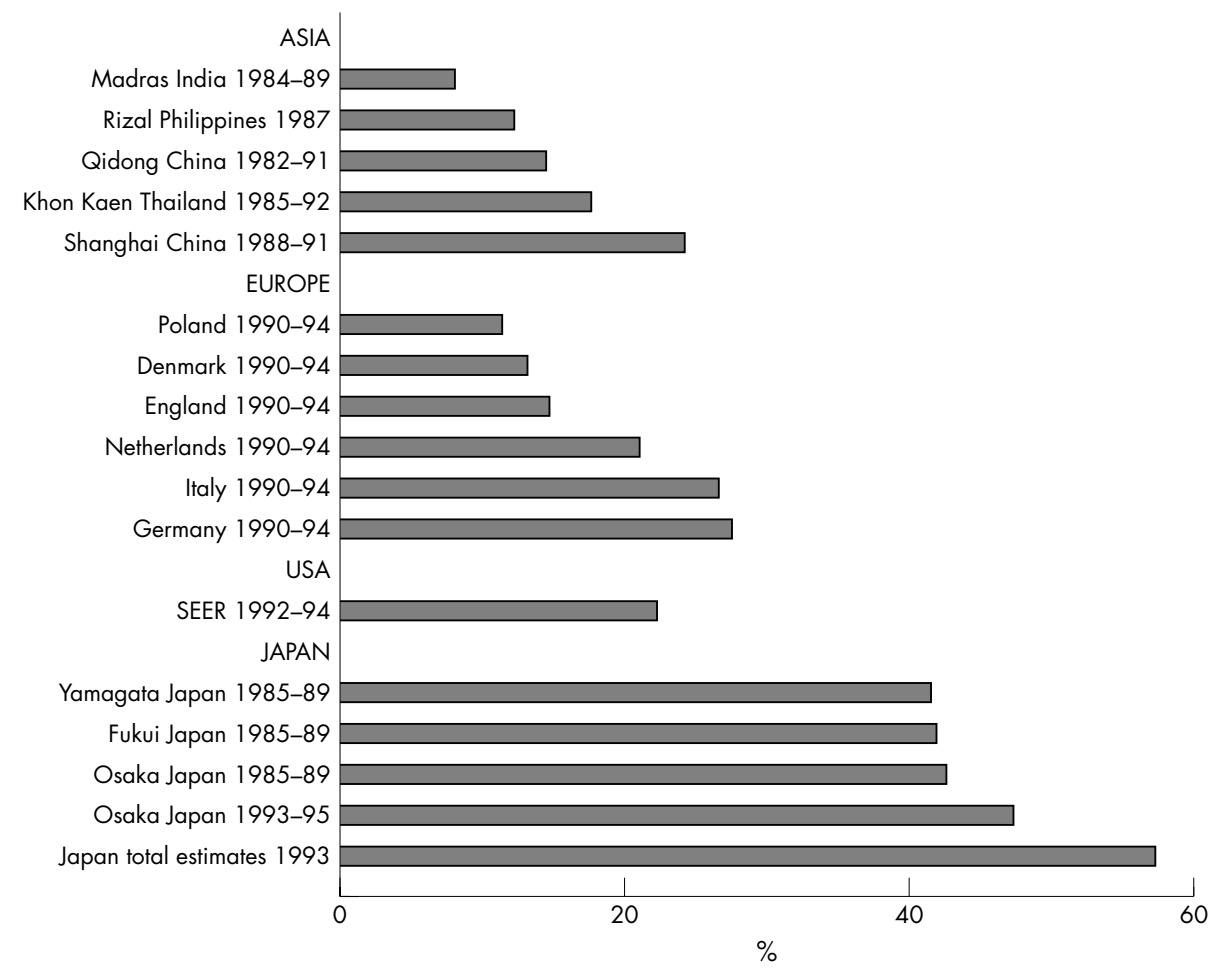

Figure 4 International comparison of five year relative survival rates (\%) of gastric cancer. Source: Ries et al, ${ }^{18}$ Sankaranarayanan ef $a l_{1}^{19}$ Sant et al, ${ }^{20}$ Ajili et al, ${ }^{21}$ and Oshima et al. ${ }^{22}$ 


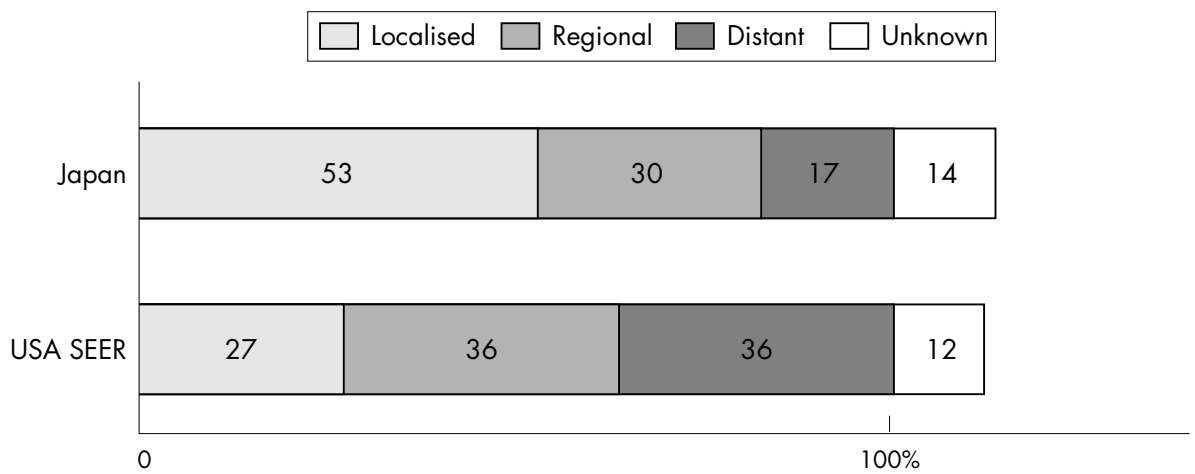

Figure 5 Stage distribution of gastric cancer in Japan and the United States (1995-2000). Source: Ries et $a^{18}$ and The Research Group for Populationbased Cancer Registration in Japan. ${ }^{23}$

\section{Key references}

- Ferlay J, Bray F, Pisani P, et al. GLOBOCAN 2002: cancer incidence, mortality and prevalence worldwide. Version 2.0. Lyon: IARC Press, 2004. (http://wwwdepdb.iarc.fr/globocan2002.htm)

- Tajima K, Kuroishi T, Oshima A, eds. Monograph on cancer research no 51. Cancer mortality and morbidity statistics. Japan and the world. Tokyo: Japanese Cancer Association/Karger, 2004.

- Parkin DM, Whelan SL, Ferlay J, et al, eds. Cancer incidence in five continents. Vol VIII. Lyon: IARC, 2002.

- Tominaga S, Kuroishi T. An ecological study on diet/ nutrition and cancer in Japan. Int J Cancer 1997;71(suppl 10):2-6.

- Miwa H, Go MF, Sato N. H pylori and gastric cancer: the Asian enigma. Am J Gastroenterol 2002;97:1 10612.

larger degree of decline seen in the mortality rate than the incidence rate if the same trends continue. It is estimated that in 2020, compared with rates in 2000, death rates will decrease by $40 \%-50 \%$, while incidence rates will decrease by $25 \%-30 \%$ (fig 2 ). On the other hand, because of the rapid aging of the population, the absolute numbers of gastric cancer deaths remain at a plateau, and those of gastric cancer incidence will show a gradual increase, especially prominent in the very old, before signs of levelling off are seen. Thus, the shift towards a downward trend will take some time to appear. $^{22}$

However, a preventable fraction by modification of risk factors can be presumed for Japanese gastric cancers. It is expected that most gastric cancers in Japan may be preventable by lifestyle modification such as salt reduction and increase in fruit and vegetable intake, together with avoidance of smoking and countermeasures against $H$ pylori infection, so that the level now evident in Western developed countries is reached.

\section{SELF ASSESSMENT QUESTIONS (TRUE (T)/FALSE (F); ANSWERS AT END OF REFERENCES)}

1. Gastric cancer is increasing worldwide.

2. More than half of gastric cancer cases occur in Eastern Asia.

3. Changes in the social environment, such as reduced salt use and increased fruit and fresh vegetable consumption through improved food storage with freezers and refrigerators is considered to have played a minor part

\section{Learning points}

- For stomach cancer, more than half of the new cases are from Eastern Asia, with 41\% from China and 11\% from Japan.

- In most countries, gastric cancer shows a constant declining trend.

- Rather than active primary and secondary prevention measures, the important parts in the reduction of gastric cancer cases in Western developed countries are generally considered to have been played by changes in the social environment, such as reduced salt use and increased fruit and fresh vegetable consumption associated with improved food storage.

- $H$ pylori infection is considered as an important risk factor for gastric cancer, but $H$ pylori infection contributes to the risk of gastric cancer presumably by interacting with other factors, including dietary habits, host factors, and the virulence of the infection.

in the reduction of gastric cancer cases in Western developed countries.

4. The prevalence of $H$ pylori infection and the incidence rate of gastric cancer are in direct proportion.

5. Mass screening is generally considered to have had an important part in the reduction of gastric cancer cases in Western developed countries.

\section{Authors' affiliations}

M Inoue, S Tsugane, Epidemiology and Prevention Division, Research Centre for Cancer Prevention and Screening, National Cancer Centre, Tokyo, Japan

Funding: this study was supported by grants in aid for Cancer Research and the Third Term Comprehensive Ten-Year Strategy for Cancer Control from the Ministry of Health, Labour and Welfare, Japan.

Conflicts of interest: none declared.

\section{REFERENCES}

1 Ferlay J, Bray F, Pisani P, et al. GLOBOCAN 2002: cancer incidence, mortality and prevalence worldwide, Version 2.0.IARC CancerBase no 5 Lyon: IARC Press, 2004, (http://www-depdb.iarc.fr/globocan2002.htm).

2 Tajima K, Kuroishi T, Oshima A, eds. Monograph on cancer research no 51. Cancer mortality and morbidity statistics. Japan and the world. Tokyo: Japanese Cancer Association/Karger, 2004.

3 Parkin DM, Whelan SL, Ferlay J, et al. Cancer incidence in five continents. Vol VIII. Lyon: IARC, 2002.

4 Parkin DM, Whelan SL, Ferlay J, et al. Cancer incidence in five continents. Vol VII. Lyon: IARC, 1997. 
5 Parkin DM, Muir CS, Whelan SL, et al. Cancer incidence in five continents. Vol VI. Lyon: IARC, 1992

6 Muir C, Waterhouse J, Mack T, et al. Cancer incidence in five continents. Vol V. Lyon: IARC, 1987.

7 Waterhouse J, Muir CS, Shanmugaratnam K, et al. Cancer incidence in five continents. Vol IV. Lyon: IARC, 1982.

8 Muir CS, Waterhouse J, Mack T, et al. Cancer incidence in five continents. Vol III. Lyon: IARC, 1976.

9 Doll R, Muir C, Waterhouse J, eds. Cancer incidence in five continents. Vol II. Geneva: Springer-Verlag, 1970.

10 Doll R, Payne P, Waterhouse J, eds. Cancer incidence in five continents. Vol I. Geneva: Springer-Verlag, 1966.

11 Ministry of Health, Labor and Welfare, Japan. Preliminary figure for vital statistics in 2003. (http://www.mhlw.go.jp/toukei/saikin/hw/jinkou/ geppo/nengai03/index.html).

12 The Research Group for Population-based Cancer Registration in Japan Cancer incidence and incidence rates in Japan in 1999: estimates based on data from 11 population-based cancer registries. Jpn J Clin Oncol 2004:34:352-6.

13 Tsugane S, de Souza JM, Costa ML Jr, et al. Cancer incidence rates among Japanese immigrants in the city of Sao Paulo, Brazil, 1969-78. Cancer Causes Control 1990;1:189-93.

14 Maruyama M, Takeshita K, Endo M, et al. Clinicopathological study of gastric carcinoma in high-and low-mortality countries: comparison between Japan and the United States. Gastric Cancer 1998;1:64-70.

15 Noguchi Y, Yoshikawa T, Tsuburaya A, et al. Is gastric carcinoma different between Japan and the United States? Cancer 2000;89:2237-46.

16 Okabayashi T, Gotoda T, Kondo H, et al. Early carcinoma of the gastric cardia in Japan: is it different from that in the West? Cancer 2000;89:2555-9

17 Inoshita N, Yanagisawa A, Arai T, et al. Pathological characteristics of gastric carcinoma in the very old. Jpn J Cancer Res 1998;89:1087-92.

18 Ries LAG, Eisner MP, Kosary CL, et al. SEER cancer statistics review, 1975 2001. Bethesda, MD: National Cancer Institute, (http://seer.cancer.gov/csr/ 1975_2001/,2004.

19 Sankaranarayanan R, Black RJ, Parkin DM, eds. Cancer survival in developing countries. Lyon: IARC, 1999

20 Sant $M$, Aareleid T, Berrino F, et al. EUROCARE Working Group. EUROCARE-3: survival of cancer patients diagnosed 1990-94-results and commentary, Ann Oncol 2003;14(suppl 5):v61-118.

21 Ajiki W, Matsuda T, Sato Y, et al. A standard methods of calculating survival rates in population-based cancer registries. Jpn J Cancer Clin 1998:44:981-93.

22 Oshima A, Kuroishi T, Tajima K, eds. Cancer statistics-incidence, mortality, and survival-2004. Japan: Shinohara Shuppan, 2004.
23 The Research Group for Population-based Cancer Registration in Japan Annual reports 1997-2003, 1998-2004. Osaka: Research Group for Population-based Cancer Registration).

24 Tsukuma H, Oshima A, Murakami R. Effect of stomach cancer screening on reducing the mortality -descriptive data in Osaka. J Gastroenterol Mass Survey 1999;37:53-8.

25 Lambert R, Guilloux A, Oshima A, et al. Incidence and mortality from stomach cancer in Japan, Slovenia and the USA. Int J Cancer 2002;97:81 1-18.

26 Tsukuma $\mathrm{H}$, Oshima A, Narahara $\mathrm{H}$, et al. Natural history of early gastric cancer: a non-concurrent, long term, follow up study. Gut 2000;47:618-21.

27 Tominaga S, Kuroishi T. An ecological study on diet/nutrition and cancer in Japan. Int J Cancer 1997;71(suppl 10):2-6.

28 World Health Organisation. Diet, nutrition and the prevention of chronic diseases. Geneva: WHO, 2003.

29 International Agency for Research on Cancer. Tobacco smoking and involuntary smoking. IARC monographs on the evaluation of the carcinogenic risk of chemicals to humans. Vol 83. Lyon: International Agency for Research on Cancer, 2004.

30 World Cancer Research Fund/American Institute for Cancer Research. Food, nutrition and the prevention of cancer: a global perspective. Washington: American Institute for Cancer Research, 1997.

31 Asaka M, Kimura T, Kudo M, et al. Relationship of Helicobacter pylori to serum pepsinogens in an asymptomatic Japanese population. Gastroenterology 1992;102:760-6.

32 Fukao A, Komatsu S, Tsubono $Y$, et al. Helicobacter pylori infection and chronic atrophic gastritis among Japanese blood donors: a cross-sectional study. Cancer Causes Control 1993;4:307-12.

33 Kikuchi S, Nakajima T, Kobayashi O, et al. Effect of age on the relationship between gastric cancer and Helicobacter pylori. Tokyo Research Group of Prevention for Gastric Cancer. Jpn J Cancer Res 2000;91:774-9.

34 The EUROGAST Study Group. Epidemiology of, and risk factors for, Helicobacter pylori infection among 3194 asymptomatic subjects in 17 populations. Gut 1993;34:1672-6.

35 Miwa H, Go MF, Sato NH. pylori and gastric cancer: the Asian enigma. Am J Gastroenterol 2002;97:1106-12.

36 Tsubono Y, Hisamichi S. Screening for gastric cancer in Japan. Gastric Cancer 2000:3:9-18.

37 Oshima A, Ajiki W, Tanaka $\mathrm{H}$, et al. Significance and usefulness of cancer registries. Int J Clin Oncol 1998;3:343-50.

\section{ANSWERS}

1. F; 2. T; 3. F; 4. F; 5. F.

11 th European Forum on Quality Improvement in Health Care 26-28 April 2006, Prague, Czech Republic Deadline 30 September 2005.

For further information and to submit online go to: www.quality.bmipg.com 